\title{
Increased prevalence and rupture status of feeder vessel aneurysms in posterior fossa arteriovenous malformations
}

\author{
Jennifer Orning, Sepideh Amin-Hanjani, Youssef Hamade, Xinjian Du, Ziad A Hage, \\ Victor Aletich, Fady Charbel, Ali Alaraj
}

Department of Neurosurgery, University of Illinois at Chicago, Chicago, Illinois, USA

\section{Correspondence to} Dr Ali Alaraj, Department of Neurosurgery, Neuropsychiatric Institute University of Illinois at Chicago 912 South Wood St, MC-799, Chicago, IL 60612, USA; alaraj@uic.edu

Received 4 August 2015 Revised 14 September 2015 Accepted 17 September 2015 Published Online First 7 October 2015
ABSTRACT

Background Posterior fossa arteriovenous malformations (AVMs) are considered to have a higher risk of poor outcome, as are AVMs with associated aneurysms. We postulated that posterior fossa malformations may be more prone to associated feeder vessel aneurysms, and to aneurysmal source of hemorrhage.

Objective To examine the prevalence and hemorrhagic risk of posterior fossa AVM-associated feeder vessel aneurysms.

Methods A retrospective review of AVMs was performed with attention paid to location and presence of aneurysms. The hemorrhage status and origin of the hemorrhage was also reviewed.

Results 571 AVMs were analyzed. Of 90 posterior fossa AVMs, 34 (37.8\%) had aneurysms (85\% feeder vessel, $9 \%$ intranidal, $15 \%$ with both). Of the 481 supratentorial AVMs, 126 (26.2\%) harbored aneurysms (65\% feeder vessel, $29 \%$ intranidal, $6 \%$ both). The overall incidence of feeder aneurysms was higher in posterior fossa AVMs, which were evident in $34.4 \%$ of infratentorial AVMs compared to $18.5 \%$ of supratentorial malformations $(p<0.01)$. The presence of intranidal aneurysms was similar in both groups (9.2\% vs $8.8 \%$ ). Feeder artery aneurysms were much more likely to be the source of hemorrhage in posterior fossa AVMs than in supratentorial AVMs ( $30 \%$ vs $7.6 \%, p<0.01)$.

Conclusions Posterior fossa AVMs are more prone to developing associated aneurysms, specifically feeder vessel aneurysms. Feeder vessel aneurysms are more likely to be the source of hemorrhage in the posterior fossa. As such, they may be the most appropriate targets for initial and prompt control by embolization or surgery due to their elevated threat.

\section{INTRODUCTION}

Brain or cerebral arteriovenous malformations (AVMs) are vascular lesions that have abnormal direct connections between the arterial and venous systems, without intervening parenchymal-perfusion small vessels. They are relatively rare-estimated to have a prevalence of $0.002-0.5 \%{ }^{12}$-and associated aneurysms have been reported from $2.7 \%$ to $21 \%$ of the time. $^{3}{ }^{4}$ These can further be subclassified as feeder (or pedicle) aneurysms or intranidal aneurysms. ${ }^{5} 6$ This excludes aneurysms on the venous drainage side of the malformation. The aneurysm location has differing implications for treatment and outcome. ${ }^{7}$ The literature conflicts as to whether intranidal ${ }^{8}$ or feeder aneurysms carry the higher risk of a hemorrhagic presentation or re-rupture before treatment, ${ }^{4}{ }^{9}$ although there is generally consensus that these are high-risk features compared with those AVMs without associated aneurysms. ${ }^{2} 45$ 8-11

Posterior fossa AVMs have been reported to be an independent predictor of increased morbidity and mortality. The percentage of AVMs presenting with hemorrhage ranges from $30 \%$ to $82 \%{ }^{12}$ Initial presentation with hemorrhage can lead to mortality rates as high as $10-30 \% .^{2}{ }^{13}$ The increased morbidity and mortality of posterior fossa AVMs has also been illustrated, ${ }^{10}{ }^{14-17}$ even though they represent only $5-15 \%$ of all intracranial AVMs. ${ }^{14} 1518$ This may be due to more frequent presentation with hemorrhage, ${ }^{4718}$ or to the more dire consequence of hemorrhage in an enclosed space with highly eloquent functional areas despite often smaller hematoma volumes after rupture. ${ }^{10}$ We hypothesize that posterior fossa malformations are also more prone to associated aneurysms-specifically feeder vessel aneurysms-and, when present, are more frequently the source of hemorrhage.

\section{METHODS}

After institutional review board approval, a retrospective review of AVMs treated at our institution from 1995 to January 2015 was evaluated. Demographic data, radiologic characteristics, and clinical parameters were collected, with attention paid to location and presence of associated aneurysms. These associated aneurysms were designated as feeder vessel aneurysms, intranidal aneurysms, or both. The hemorrhage status and origin of the hemorrhage was also reviewed. Two endovascular neurosurgeons determined the site of hemorrhage origination by radiologic review of the presentation CT scan and cerebral angiogram. An extensive literature review was performed for comparison of results with published reports.

\section{Statistical analysis}

The demographic data and proportion of AVM patients with feeder aneurysms were compared between a supratentorial and infratentorial location using the $\chi^{2}$ test. ORs were used to evaluate the source of bleeding from a feeder aneurysm in infratentorial AVMs compared with supratentorial AVMs. Statistical analyses were performed using SAS software V.9.4 (SAS Institute, Cary, North Carolina, USA). 


\section{RESULTS}

\section{Patient characteristics}

A total of 571 AVMs that had identifiable locations were analyzed. The age range of the patients was 19 days to 87 years (average 41 years) and the gender was evenly distributed, with 288 women and 283 men. Two hundred and eighty-four $(49.6 \%)$ of these AVMs initially had a hemorrhagic presentation. One hundred and sixty AVMs (28.0\%) had associated aneurysms, $120(21.0 \%)$ of which had associated feeder aneurysms. Of the 571 AVMs, 90 were infratentorial.

\section{Incidence of feeder aneurysms}

Of the 90 AVMs located in the posterior fossa (including cerebellar and brainstem locations), 34 (37.8\%) had aneurysms: 29 $(85 \%)$ with at least one feeder vessel aneurysm, 3 (9\%) with intranidal aneurysms, and $5(15 \%)$ with both. Of the 481 supratentorial AVMs, 126 (26.2\%) harbored aneurysms, 82 (65\%) of which were feeder aneurysms, 37 (29\%) intranidal, and 7 (6\%) both. The overall incidence of aneurysms was appreciably higher in posterior fossa AVMs. This association was most pronounced for feeder aneurysms, which were evident in $34.4 \%$ of infratentorial AVMs compared with $18.5 \%$ of supratentorial malformations $(p<0.01)$. The incidence of intranidal aneurysms was similar in supratentorial and infratentorial locations $(9.2 \%$ vs $8.9 \%$; table 1$)$.

\section{Feeder aneurysm rupture status}

When evaluating for rupture site, 18 of 60 hemorrhages in the posterior fossa could be attributed to a feeder aneurysm, yielding a 58\% rupture incidence for those aneurysms, and accountable for $30 \%$ of ruptures among infratentorial AVMs. In comparison, 17 of 224 supratentorial hemorrhages could be clearly attributed to a feeder aneurysm, yielding a $19 \%$ aneurysm rupture incidence and accounting for $7.6 \%$ of total supratentorial AVM hemorrhages $(\mathrm{p}<0.01)$. This amounts to an OR of rupture from feeder aneurysms at the time of presentation of 5.86 (CI 2.4 to $14.2 ; \mathrm{p}=0.001$ ) for infratentorial versus supratentorial hemorrhages.

\section{Illustrative case}

A middle-aged patient with no past medical history presented with 1 week of unrelenting headache, which had initially occurred postcoitally. Initial head CT demonstrated a

Table 1 Distribution of patients with infratentorial versus supratentorial AVMs, with hemorrhagic presentation between the two groups

\begin{tabular}{|c|c|c|c|c|c|}
\hline & \multicolumn{2}{|c|}{ Infratentorial } & \multicolumn{2}{|c|}{ Supratentorial } & \multirow[b]{2}{*}{ Totals } \\
\hline & $\begin{array}{l}\text { No of } \\
\text { patients }\end{array}$ & $\%$ & $\begin{array}{l}\text { No of } \\
\text { patients }\end{array}$ & $\%$ & \\
\hline Total & 90 & 15.76 & 481 & 84.24 & 571 \\
\hline Cerebellar & 78 & 13.66 & & & \\
\hline Brainstem & 12 & 2.10 & & & \\
\hline Ruptured & 60 & 66.67 & 224 & 46.57 & 284 \\
\hline Total aneurysms & 34 & & 126 & & 160 \\
\hline Feeder & 29 & 37.8 & 89 & 18.50 & \\
\hline Intranidal & 3 & 9.0 & 44 & 9.15 & \\
\hline Both & 5 & 15 & 7 & 1.46 & \\
\hline Bleed from feeder & 18 & 58.06 & 17 & 19.10 & \\
\hline
\end{tabular}

AVM, arteriovenous malformation. hemorrhage measuring $2 \mathrm{~cm} \times 8 \mathrm{~mm}$ around the cerebellar vermis and he was admitted to the neurosurgical service (figure 1A). CT angiography (CTA) showed an underlying vermian AVM, and the initial angiogram demonstrated a Spetzler-Martin grade II, Spetzler-Ponce grade A malformation measuring $2 \mathrm{~cm}$ and fed by the superior cerebellar artery (SCA) and posterior inferior cerebellar artery (PICA) (figure 1B). It drained into the straight sinus, as well as the transverse sinus and torcular herephili. There were associated feeder and intranidal aneurysms of the SCA (figure 1C) and PICA. Embolization of all feeder aneurysms was performed using n-butyl cyanoacrylate (n-BCA) (Codman Neuro, Raynham, Massachusetts, USA) in one session (figure 1D). Postembolization angiographic images demonstrated occlusion of all aneurysms. Two weeks later, suboccipital craniotomy was performed for resection of the residual malformation with no resultant complications or symptoms (figure 1E).

\section{DISCUSSION}

Comparison of data in the literature on the topic of AVM-associated aneurysms can be difficult due to varying classification schemes and differing denominators for reported prevalence. As shown in table 2, the occurrence of associated aneurysms is listed as the percentage of total AVMs (ie, supratentorial and infratentorial) in some papers, while others only evaluated infratentorial malformations. Some only cataloged ruptured presentations while others reported all AVMs in an institution. The aneurysms themselves are described alternately as 'feeder', 'proximal', or 'prenidal' aneurysms to separate them from 'intranidal'/'nidal' or 'remote'/'unassociated' aneurysms. For instance, Platz et $a l^{19}$ classifies AVM-associated aneurysms as feeding (type 1), nidal (type 2), or unassociated (type 3), but further divides type 1 into $1 \mathrm{a}$ and $\mathrm{b}$, where $1 \mathrm{a}$ is closer to the circle of Willis than the malformation itself while the opposite is true with type $1 \mathrm{~b}$. In contrast, Yu et al ${ }^{20}$ used a four-tier classification system where I was unassociated, II was flow-related but at the proximal portion of a feeding artery, III was 'dissecting type' on a feeding artery, and IV was intranidal. Some papers do not subclassify feeder, remote, or intranidal aneurysms at all. However, the overall incidence of aneurysms associated with AVMs from our literature review is $2.6-47 \%$. In the posterior fossa specifically, the incidence is $20.8-47 \%$ (table 2).

Our results support previous implications that feeder aneurysms are more common infratentorially. ${ }^{21-24}$ The reason for this increased incidence and predilection for hemorrhage is unclear, although the differential impact of AVM hemodynamics in smaller posterior fossa vessels may be relevant. Increased wall shear stress (WSS) and, to some degree, smaller vessel size has previously been demonstrated as a risk factor for supratentorial feeder vessels to be associated with aneurysms; ${ }^{25-27}$ thus, smaller vessel feeders such as the PICA and SCA, as encountered in the posterior fossa, may be more prone to developing increased WSS in the setting of high AVM flows and, consequently, aneurysms. $^{2126}$

This study is drawn from one of the largest databases of AVMs reported. Only three other groups have reported on a volume of patients larger than this one, ranging from 600-662, some by joining data from multiple centers. ${ }^{6} 823$ In correlation with the majority of the literature, we demonstrate no statistically significant gender predilection for hemorrhage or associated feeder aneurysms, although articles such as those by Platz et al ${ }^{19}$ and Thompson $e t a l^{23}$ did find a difference, with increased associated aneurysms and hemorrhagic presentation, respectively, in women. In our study, slightly more men presented with hemorrhage, although more women had associated aneurysms. 

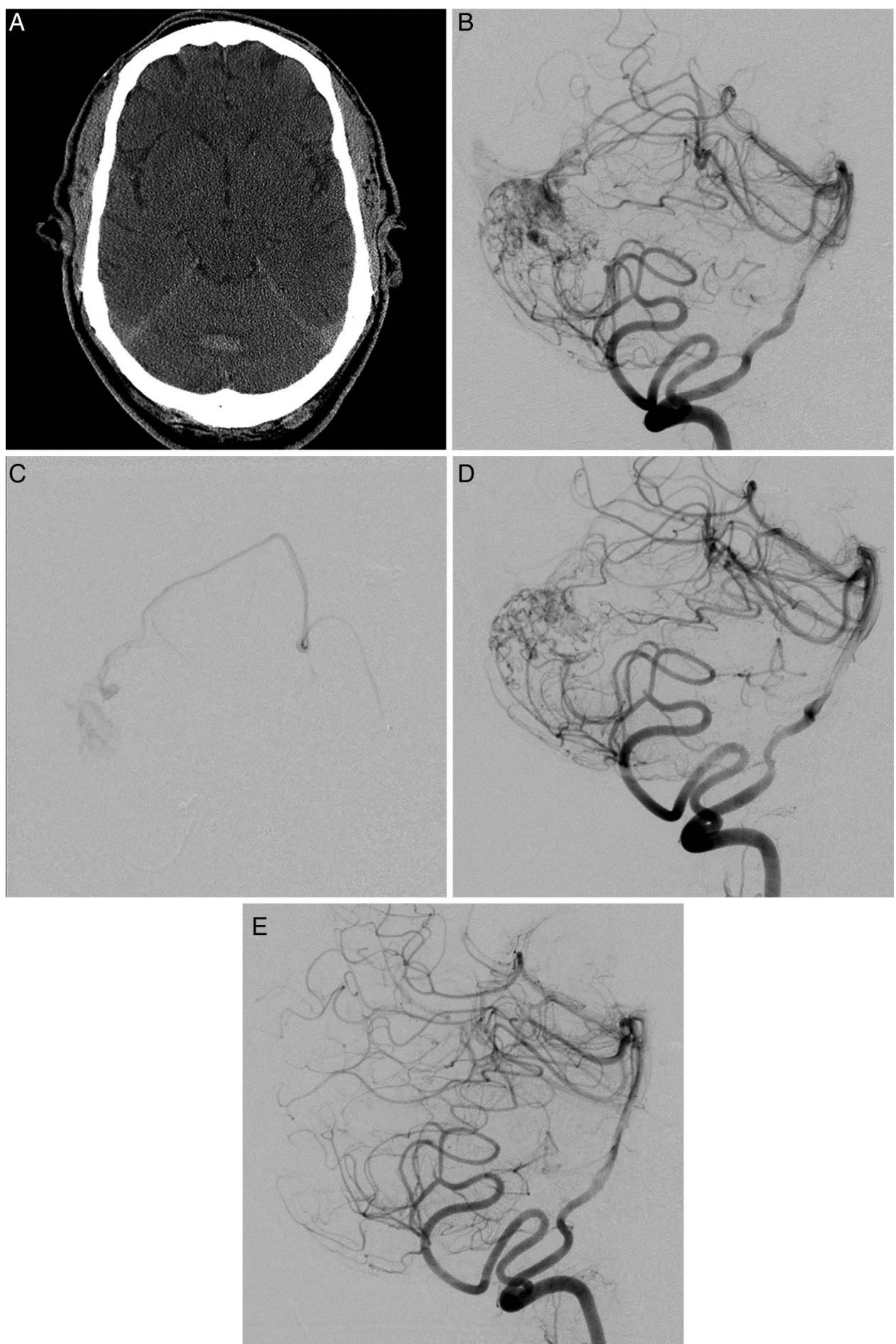

Figure 1 (A) Initial non-contrast head CT and CT angiography showing vermian cerebellar hemorrhage and right paravermian arteriovenous malformations (AVM). (B) Initial angiogram image, lateral, demonstrating a paravermian Spetzler-Ponce grade A AVM with associated posterior inferior cerebellar artery (PICA) and superior cerebellar artery (SCA) aneurysms. (C) Selective catheterization of right SCA pre-embolization. (D) Post-embolization angiogram showing absence of associated aneurysms with residual AVM nidus. (E) Postoperative angiogram, lateral, demonstrating complete resection of the AVM.

However, we demonstrate, in a large single-center sample, an increased risk of hemorrhagic source specifically from AVM-associated aneurysms in the posterior fossa in comparison with supratentorial locations, with an OR of 5.86.

AVMs have been represented in the literature most recently due to controversy over the best treatment regimen, which has been heavily debated, especially for lower grade lesions. The
ARUBA trial made sweeping recommendations to leave all of these malformations to conservative medical management only. There has been significant discussion as to whether low-grade lesions should, instead, be addressed using surgical resection as the primary modality. Many authors and experts advocate a multimodality approach to many of these malformations, ${ }^{16} 2228$ especially high-grade lesions. The literature suggests that 
Table 2 Literature review presenting the incidence of associated aneurysms with AVMs with respect to location and hemorrhagic presentation

\begin{tabular}{|c|c|c|c|c|}
\hline $\begin{array}{l}\text { Authors } \\
\text { (reference) }\end{array}$ & $\begin{array}{l}\text { Incidence }(\%) \text { of feeder } \\
\text { aneurysms in total intracranial } \\
\text { AVMs }\end{array}$ & $\begin{array}{l}\text { Incidence (\%) of feeder } \\
\text { aneurysms in supratentorial } \\
\text { AVMs }\end{array}$ & $\begin{array}{l}\text { Incidence }(\%) \text { of feeder } \\
\text { aneurysms in infratentorial } \\
\text { AVMs }\end{array}$ & $\begin{array}{l}\text { AVMs with feeders that } \\
\text { presented with haemorrhage } \\
(\%)\end{array}$ \\
\hline Abla et $a l^{10}$ & $31.8(49 / 154)$ & - & - & - \\
\hline de Costa et $a l^{11}$ & - & - & $17.4(17 / 98)$ & - \\
\hline Kouznetsov et $a l^{18}$ & $6(14 / 233)$ & - & - & - \\
\hline Lasjaunias et $a l^{5}$ & $13(13 / 101)$ & - & - & 57 of total AVMs with aneurysms \\
\hline Lv et $a l^{9}$ & $7.9(24 / 302)$ & - & - & - \\
\hline Magro et $a l^{17}$ & - & - & $47(16 / 34)$ & - \\
\hline Meisel et $a l^{8}$ & $27.8(184 / 662)$ & - & - & $57(46 / 81)$ \\
\hline Platz et $a l^{19}$ & $35.2(76 / 216)$ & - & - & $59.3(35 / 59)$ total \\
\hline Redekop et $a l^{6}$ & $11.2(71 / 632)$ & - & - & $40.8(29 / 71)$ \\
\hline Schmidt et $a l^{21}$ & - & $5(21 / 417)$ & $25(14 / 57)$ & - \\
\hline Stapf et $a l^{4}$ & $17(77 / 463)$ & - & - & $55.8(43 / 77)$ \\
\hline Stein et $a l^{22}$ & - & - & $22.6(12 / 53)$ & - \\
\hline Thompson et $a l^{23}$ & $7.5(45 / 600)$ & - & - & $51.1(23 / 45)$ \\
\hline Westphal et $a^{24}$ & - & $2.6(5 / 196)$ & $20.8(5 / 24)$ & - \\
\hline Yang et $a l^{12}$ & - & - & $32.8(20 / 61)$ & - \\
\hline
\end{tabular}

AVM, arteriovenous malformation.

posterior fossa AVMs represent an especially dangerous subset of lesions, with associated aneurysms an especially high-risk feature. We suggest, as have other authors, ${ }^{29}{ }^{30}$ that immediate elimination of the feeder aneurysm should be a priority, often by endovascular means, if it cannot be addressed during the surgical resection easily.

In this study, the designation of the site of origin of the hemorrhage was somewhat subjective as this could not be performed blind to the location of the AVM. However, every effort was made to report the source definitively only if the location was disparate enough to be clear and often reinforced by the location of n-BCA liquid embolisate after embolization on CT. The hemorrhage rates reported to be attributable to the feeder aneurysms are, if anything, likely to be underestimated. Only those that could be definitively attributed to the aneurysm due to some distance or an appropriate trajectory were documented as such, whereas those that could have been either from the aneurysm or the AVM itself-or an intranidal aneurysm-were not. Other study limitations include the single-center nature of the data; as a tertiary referral center, our data may not be generalizable as the true incidence of aneurysms in AVMs. However, referral bias is unlikely to be AVM location-specific, thus our comparison between supratentorial and infratentorial locations maintains validity. Given the retrospective nature of the data, we cannot make definitive statements as to the prospective risk of hemorrhage attributable to associated aneurysms, but we have identified the increased likelihood that posterior fossa AVM feeder vessel aneurysms are significantly more likely to be the source of hemorrhage in ruptured AVMs of this location.

\section{CONCLUSION}

Posterior fossa AVMs are more prone to developing associated aneurysms, specifically feeder vessel aneurysms. Compared with supratentorial AVMs, feeder vessel aneurysms are also more likely to be the source of hemorrhage in the posterior fossa. These data support targeting posterior fossa feeder aneurysms for initial and prompt control by embolization or surgery.

Acknowledgements Part of this manuscript was presented at the 12th Annual Meeting of the Society of Neurolnterventional Surgery in San Francisco, California, USA in July 2015.
Contributors JO: design of the work, including the acquisition, analysis, and interpretation of data, drafting the paper, revising it critically for important intellectual content, and contribution to the final approval of the version to be published. SA-H: design of the work, drafting the work, revising it critically for intellectual content, and contribution to the final approval of the version to be published. YH: acquisition of data, analysis, and final approval of the version to be published. XD: statistical analysis. ZH: design of the work and final approval of the version to be published. VA: design of the work, interpretation of the results, drafting of the paper and final approval. FC: revising the manuscript and final approval of results. AA: design of the work, drafting the work, revising it critically for important intellectual content, and final approval of the version to be published.

Funding This study is partially supported by the Dr Ralph and Marian Falk Medical Research Trust, fund \# 629138.

Competing interests $A A$ and VA are consultants for Cordis-Codman.

Ethics approval Ethics approval was obtained from the University of Illinois at Chicago Institutional Review Board.

Provenance and peer review Not commissioned; externally peer reviewed.

Data sharing statement All relevant data have been presented in this paper. The entire data are protected and available from the principal investigator. More detailed clinical and demographic data are unidentified and locked in the office of the corresponding author and are available on request.

\section{REFERENCES}

1 Fleetwood IG, Steinberg GK. Arteriovenous malformations. Lancet 2002;359:863-73.

2 Zacharia BE, Vaughan KA, Jacoby $A$, et al. Management of ruptured brain arteriovenous malformations. Curr Atheroscler Rep 2012;14:335-42.

3 Kaptain GJ, Lanzino G, Do HM, et al. Posterior inferior cerebellar artery aneurysms associated with posterior fossa arteriovenous malformation: report of five cases and literature review. Surg Neurol 1999:51:146-52.

4 Stapf C, Mohr JP, Pile-Spellman J, et al. Concurrent arterial aneurysms in brain arteriovenous malformations with haemorrhagic presentation. I Neurol Neurosurg Psychiatry 2002;73:294-8.

5 Lasjaunias P, Piske R, Terbrugge K, et al. Cerebral arteriovenous malformations (C. AVM) and associated arterial aneurysms (AA). Analysis of 101 C. AVM cases, with 37 AA in 23 patients. Acta Neurochir (Wien) 1988;91:29-36.

6 Redekop G, TerBrugge K, Montanera W, et al. Arterial aneurysms associated with cerebral arteriovenous malformations: classification, incidence, and risk of hemorrhage. J Neurosurg 1998;89:539-46.

7 Kondziolka D, Nixon BJ, Lasjaunias P, et al. Cerebral arteriovenous malformations with associated arterial aneurysms: hemodynamic and therapeutic considerations. Can J Neurol Sci 1988;15:130-4.

8 Meisel HJ, Mansmann U, Alvarez $\mathrm{H}$, et al. Cerebral arteriovenous malformations and associated aneurysms: analysis of 305 cases from a series of 662 patients. Neurosurgery 2000;46:793-800; discussion 800-2.

9 Lv X, Li Y. Patient age, hemorrhage patterns and AVM outcomes. World Neurosurg. Published Online First 22 May 2015. 
10 Abla AA, Nelson J, Rutledge WC, et al. The natural history of AVM hemorrhage in the posterior fossa: comparison of hematoma volumes and neurological outcomes in patients with ruptured infra- and supratentorial AVMs. Neurosurg Focus 2014;37:E6.

11 da Costa L, Thines L, Dehdashti AR, et al. Management and clinical outcome of posterior fossa arteriovenous malformations: report on a single-centre 15-year experience. J Neurol Neurosurg Psychiatry 2009;80:376-9.

12 Yang W, Caplan JM, Ye X, et al. Racial associations with hemorrhagic presentation in cerebral arteriovenous malformations. World Neurosurg 2015;84:461-9.

13 Wilkins RH. Natural history of intracranial vascular malformations: a review. Neurosurgery 1985;16:421-30.

14 Arnaout OM, Gross BA, Eddleman CS, et al. Posterior fossa arteriovenous malformations. Neurosurg Focus 2009;26:E12.

15 Batjer H, Suss RA, Samson D. Intracranial arteriovenous malformations associated with aneurysms. Neurosurgery 1986;18:29-35.

16 Lawton MT, Hamilton MG, Spetzler RF. Multimodality treatment of deep arteriovenous malformations: thalamus, basal ganglia, and brain stem. Neurosurgery 1995;37:29-35; discussion 35-6.

17 Magro E, Chainey J, Chaalala C, et al. Management of ruptured posterior fossa arteriovenous malformations. Clin Neurol Neurosurg 2015;128:78-83.

18 Kouznetsov E, Weill A, Ghostine JS, et al. Association between posterior fossa arteriovenous malformations and prenidal aneurysm rupture: potential impact on management. Neurosurg Focus 2014;37:E4.

19 Platz J, Berkefeld J, Singer OC, et al. Frequency, risk of hemorrhage and treatment considerations for cerebral arteriovenous malformations with associated aneurysms. Acta Neurochir (Wien) 2014;156:2025-34.

20 Yu JL, Yang S, Luo Q, et al. Endovascular treatment of intracranial ruptured aneurysms associated with arteriovenous malformations: a clinical analysis of 14 hemorrhagic cases. Interv Neuroradiol 2011;17:78-86.
21 Schmidt NO, Reitz M, Raimund F, et al. Clinical relevance of associated aneurysms with arteriovenous malformations of the posterior fossa. Acta Neurochir Suppl 2011;112:131-5

22 Stein KP, Wanke I, Schlamann M, et al. Posterior fossa arterio-venous malformations: current multimodal treatment strategies and results. Neurosurg Rev 2014;37:619-28.

23 Thompson RC, Steinberg GK, Levy RP, et al. The management of patients with arteriovenous malformations and associated intracranial aneurysms. Neurosurgery 1998:43:202-11; discussion 211-2.

24 Westphal M, Grzyska U. Clinical significance of pedicle aneurysms on feeding vessels, especially those located in infratentorial arteriovenous malformations. J Neurosurg 2000;92:995-1001.

25 Alaraj A, Shakur SF, Amin-Hanjani S, et al. Changes in wall shear stress of cerebral arteriovenous malformation feeder arteries after embolization and surgery. Stroke 2015:46:1216-20.

26 Shakur SF, Amin-Hanjani S, Mostafa H, et al. Hemodynamic characteristics of cerebral arteriovenous malformation feeder vessels with and without aneurysms. Stroke 2015;46:1997-9.

27 Rossitti S, Svendsen P. Shear stress in cerebral arteries supplying arteriovenous malformations. Acta Neurochir (Wien) 1995;137:138-45.

28 Blackburn SL, Ashley WW Jr, Rich KM, et al. Combined endovascular embolization and stereotactic radiosurgery in the treatment of large arteriovenous malformations. J Neurosurg 2011;114:1758-67.

29 Kominami S, Watanabe A, Kobayashi S, et al. Ruptured feeder aneurysm associated with cerebellar arteriovenous malformation. J Nippon Med Sch 2012;79:296-300.

30 Signorelli F, Gory B, Pelissou-Guyotat I, et al. Ruptured brain arteriovenous malformations associated with aneurysms: safety and efficacy of selective embolization in the acute phase of hemorrhage. Neuroradiology 2014;56:763-9. 